\title{
Gastrin is a target of the $\beta$-catenin/TCF-4 growth-signaling pathway in a model of intestinal polyposis
}

\author{
Theodore J. Koh, ${ }^{1}$ Clemens J. Bulitta, ${ }^{1}$ John V. Fleming, ${ }^{1}$ Graham J. Dockray, ${ }^{2}$ \\ Andrea Varro, ${ }^{2}$ and Timothy C. Wang ${ }^{1}$ \\ ${ }^{1}$ Gastrointestinal Unit, Department of Medicine, Massachusetts General Hospital, Boston, Massachusetts, USA \\ ${ }^{2}$ The Physiology Laboratory, University of Liverpool, Liverpool, United Kingdom
}

Address correspondence to: Timothy Wang, Jackson 724, Massachusetts General Hospital, Boston, Massachusetts 02114, USA. Phone: (617) 726-9228; Fax: (617) 726-3673; E-mail: wang@helix.mgh.harvard.edu.

Theodore J. Koh and Clemens J. Bulitta contributed equally to this work.

Received for publication January 27, 2000, and accepted in revised form July 11, 2000.

\begin{abstract}
Mutations in the adenomatous polyposis coli (APC) tumor suppressor gene occur in most colorectal cancers and lead to activation of $\beta$-catenin. Whereas several downstream targets of $\beta$-catenin have been identified (c-myc, cyclin D1, PPAR $)$ ), the precise functional significance of many of these targets has not been examined directly using genetic approaches. Previous studies have shown that the gene encoding the hormone gastrin is activated during colon cancer progression and the less-processed forms of gastrin are important colonic trophic factors. We show here that the gastrin gene is a downstream target of the $\beta$-catenin/TCF- 4 signaling pathway and that cotransfection of a constitutively active $\beta$-catenin expression construct causes a threefold increase in gastrin promoter activity. $\mathrm{APC}^{\mathrm{min}-/_{+}}$mice overexpressing one of the alternatively processed forms of gastrin, glycine-extended gastrin, show a significant increase in polyp number. Gastrin-deficient $\mathrm{APC}^{\mathrm{min}-{ }^{-+}}$mice, conversely, showed a marked decrease in polyp number and a significantly decreased polyp proliferation rate. Activation of gastrin by $\beta$-catenin may therefore represent an early event in colorectal tumorigenesis and may contribute significantly toward neoplastic progression. The identification of gastrin as a functionally relevant downstream target of the $\beta$-catenin signaling pathway provides a new target for therapeutic modalities in the treatment of colorectal cancer.
\end{abstract}

J. Clin. Invest. 106:533-539 (2000).

\section{Introduction}

Inactivation of the adenomatosis polyposis coli (APC) tumor suppressor gene is an early event in the development of colon cancer, occurring in up to $80 \%$ of adenomatous polyps (1). It is also responsible for familial adenomatous polyposis, a genetic disorder leading to hundreds of adenomatous polyps in both the small and large intestine that results in colon cancer in all affected individuals by the age of 40 (2). It has been shown that a major function of APC is to downregulate cytosolic levels of $\beta$-catenin, preventing formation of $\beta$ catenin/T-cell factor- 4 (TCF-4) complexes $(3,4)$. The $\beta$ catenin/TCF- 4 complex is transported into the nucleus where it acts as a transcription factor (5-6). TCF-4-deficient mice have no proliferating cells in their intestinal crypts (7), suggesting that the $\beta$-catenin/TCF- 4 complex is an important regulator of intestinal proliferation.

Several downstream targets for $\beta$-catenin/TCF- 4 have been identified. $C-m y c$, an oncogene which is overexpressed in adenomatous polyps as well as in colon cancer, has been shown to be upregulated by the $\beta$ catenin/TCF-4 transcription factor by its binding to TCF-4-binding elements (CCTTTGATT and GCTTGATC) on the $c-m y c$ promoter (8). Similar results were obtained for cyclin D1 (9), which, like c-myc, is important in cellcycle regulation and is upregulated during colon cancer progression, and PPAR $\delta$, a nuclear receptor thought to play a role in colonic maturation/differentiation that is upregulated in cancers and downregulated by nonsteroidal anti-inflammatory drugs (10). Whereas these downstream targets of $\beta$-catenin/TCF- 4 are likely to be important in the pathogenesis of colon cancer, the precise functional significance of these targets has not been directly examined using genetic approaches.

Gastrin is a gastrointestinal hormone and growth factor, and, like c-myc and cyclin D1, is upregulated in adenomatous polyps $(11)$ and in colon cancer $(12,13)$. It has been shown previously that the incompletely processed products of gastrin gene expression (progastrin and glycine-extended gastrin) that predominate in the normal fetal and adult colon (14), as well as in colon cancer $(12,13)$, are capable of inducing colonic proliferation when overexpressed in transgenic mice $(15,16)$. A colon-specific growth factor role has been confirmed in gastrin-deficient mice, which show a decrease in colonic proliferation that can be corrected through infusion of glycine-extended gastrin (17). Our analysis of the 1.3-kb human gastrin-promoter sequence has revealed several potential TCF- 4 consensus binding sites (Figure 1a). We therefore hypothesize that gastrin also may be a biologically active downstream target of the $\beta$ catenin/TCF-4 signaling pathway. 


\section{Methods}

Northern blot studies. HT-29-APC and HT-29-GAL cell lines were used in this experiment (a kind gift of Kenneth Kinzler, Johns Hopkins Oncology Center, Baltimore, Maryland, USA). Cell culture and zinc induction $\left(120 \mu \mathrm{M} \mathrm{ZnCl}_{2}\right)$ was performed as described previously (18). Total RNA was isolated with TRIZOL (Life Technologies Inc., Gaithersburg, Maryland, USA). Twenty micrograms of RNA was loaded per lane. The blot was probed with a human gastrin exon 2 riboprobe (16) and, after the blot was stripped, with a probe to GAPDH. The Northern blots were then scanned by an Arcus II scanner (AGFA, Lerverkusen, Germany), and densitometry was performed using the NIH Image 1.62 program (NIH, Bethesda, Maryland, USA) on blots representing four independent experiments.

Cell-transfection studies. Exponentially growing HeLa cells were cultured in DMEM with $10 \%$ FBS and were transfected with Lipofectamine (Life Technologies Inc.) using $0.4 \mu \mathrm{g}$ gastrin promoter-luciferase reporter construct (a kind gift of Daniel Chung, Massachusetts General Hospital; see ref. 19), and $0.4 \mu \mathrm{g}$ constitutively active $\beta$-catenin (a kind gift of Eric Fearon, University of Michigan Medical Center, Ann Arbor, Michigan, USA; see ref. 20) plus or minus $0.4 \mu \mathrm{g}$ dominant-negative TCF-4 (a kind gift of Kenneth Kinzler; see ref. 18) per well of a six-well plate. Transfection efficiency was controlled by cotransfection with $0.2 \mu \mathrm{g}$ of a $\beta$-galactosidase expression construct. Cells were harvested 24 hours after transfection and luciferase assays were performed as described previously (19).

Generation of MTI/G-Gly APC $\mathrm{min-/+}^{\text {mice. }} \mathrm{MTI} / \mathrm{G}-\mathrm{Gly}$ mice, which overexpress glycine-extended gastrin, were generated as described previously in the FVB mouse background (16). The MTI/G-Gly and control FVB mice were crossed to the $\mathrm{C} 57 \mathrm{BL} / 6 \mathrm{APC}^{\mathrm{min}-/_{+}}$mice and the resulting pups were screened for the MTI/G-Gly transgene and the min mutation (21) as described previously. Twenty MTI/G-Gly APC $\mathrm{Amin}-/+^{\text {mice }}$ and 20 control APC ${ }^{\text {min-/++ }}$ mice were used in this study.

Generation of gastrin-deficient $A P C^{\text {min-/+ }}$ mice. Gastrindeficient mice were generated in the C57BL/ $6 \times$ SV129 background as described previously (17). They were mated to C57BL/6 APC min-/+ mice (The Jackson Labs, Bar Harbor, Maine, USA) and the resulting pups were screened for heterozygosity for the min mutation (21) and for the gastrin-null gene (17) as described previously. The resulting heterozygotes were then mated to gastrin-deficient mice, and those that were gastrin deficient and heterozygous for the min mutation were used for analysis. As controls, the first generation mice that were heterozygous for both the min mutation and the gastrin-null gene were mated to wild-type C57BL/6× SV129 mice, and those mice that were heterozygous for the min mutation and homozygous for the wild-type gastrin allele were used as controls. Fifteen gastrin-deficient $\mathrm{APC}^{\mathrm{min}-/+}$ mice and 15 control $\mathrm{APC}^{\mathrm{min}-/+}$ mice were used for polyp analysis, and fifteen additional mice from each group were used for survival analysis.
Polyp-number determination. Fifteen gastrin-deficient $\mathrm{APC}^{\text {min-/+ }}$ mice, 15 control C57BL/6 $\mathrm{APC}^{\mathrm{min}-/+}$ mice, 20 MTI/G-Gly $\mathrm{APC}^{\mathrm{min}-/^{+}}$mice, and 20 control FVB $\mathrm{APC}^{\mathrm{min}-/^{+}}$mice were sacrificed at 6 months. The mice were weighed, serum was obtained, and the small and large intestine were isolated. They were then placed into a Petri dish containing PBS, and examined with a Zeiss Stemi 1000 dissecting microscope (Carl Zeiss Inc., Jena, Germany) to determine polyp number and size. Only polyps that were $1 \mathrm{~mm}$ or larger were counted. Three large polyps (>3 $\mathrm{mm}$ ) were obtained from each mouse for DNA analysis. The intestinal tissue was then placed in Carnoy's fixative overnight and embedded in paraffin wax for histological analysis.

Incorporation of 5-bromo-2'-deoxyuridine. One hour before sacrifice, 15 gastrin-deficient and control $\mathrm{APC}^{\mathrm{min}-/+}$ mice were injected with 5-bromo-2'-deoxyuridine (BrdU; 50 $\mathrm{mg} / \mathrm{kg}$ intraperitoneally). The intestines were excised and fixed in Carnoy's fixative overnight. Immunohistochemical staining was performed with BrdU antibody (DAKO, Glostrup, Denmark) as described previously (16). Up to three 1-2 mm, 2-3 mm, and greater than 3$\mathrm{mm}$ polyps were analyzed for each mouse. The labeling index was defined as the number of positively stained cells divided by the total number of cells in each polyp.

Detection of k-ras mutations. Polyps greater than $3 \mathrm{~mm}$ were microdissected away from the normal colonic epithelium using a Zeiss Stemi 1000 dissecting microscope (Carl Zeiss Inc.) and digested in a solution containing $50 \mathrm{mM}$ Tris, $\mathrm{pH} 8.0,0.5 \%$ Triton $\mathrm{X}-100$, and proteinase $\mathrm{K}(1 \mathrm{mg} / \mathrm{mL})$ overnight at $55^{\circ} \mathrm{C}$, and then boiled for 10 minutes to inactivate the proteinase K. PCR analysis was then performed as described previously (22).

Statistical analysis. The results were expressed as means plus or minus SEM. ANOVA test for random differences, Student's $t$ test, and log-rank tests were applied. $P<0.05$ was considered statistically significant.

\section{Results}

Gastrin is a downstream target of the $\beta$-catenin/TCF-4 signaling pathway. To determine if gastrin was a potential downstream target of $\beta$-catenin, the zinc-inducible colon cancer cell lines HT-29-APC and HT-29-GAL were used to test this hypothesis. This cell line contains inactive endogenous APC alleles and has been shown previously to produce full-length APC protein that binds $\beta$-catenin and significantly reduces $\beta$-catenin signaling in response to zinc induction (18). Induction of wild-type APC by zinc led to a significant $(32.5 \pm 11.1 \%$, $P=0.03)$ decrease in gastrin mRNA expression, whereas induction of the $\beta$-galactosidase gene had no effect on gastrin mRNA levels (Figure 1b).

The area of $\beta$-catenin responsiveness resides in the region between -103 and -93 on the gastrin promoter. Induction of the gastrin promoter by $\beta$-catenin was confirmed by transient transfection studies in HeLa cells using a $1.3-\mathrm{kb}$ gastrin promoter-luciferase reporter construct. HeLa cells were chosen because they have been shown previously to express a sufficient level of TCF-4 to support $\beta$ - 
catenin-dependent activation of a $\beta$-catenin/TCF-4 regulated promoter (9). Cotransfection with a constitutively active $\beta$-catenin expression construct resulted in a significant threefold increase in gastrin promoter activity (Figure 1c). This effect could be inhibited significantly by cotransfection with a dominant-negative TCF-4 expression construct. Serial deletion constructs of the gastrin promoter suggest that a critical cis-acting element mediates $\beta$-catenin responsiveness between -110 and -93 of the human gastrin promoter (Figure 1c). Located within this region is a potential TCF-binding site -103 CCCATTCCT -93. We then generated heterologous promoter constructs by inserting either the wild-type TCF4-binding site found on the human gastrin promoter from -103 to -90 , a mutated TCF-4-binding site from -103 to -90 , and a consensus TCF-4-binding site that would correlate with the region from -103 to -90 upstream of a thymidine kinase promoter-luciferase reporter construct pT81 (Figure 1d) (23). Transfection studies with these constructs reveal that the wild-type gastrin-promoter sequence from -103 to -90 can confer $\beta$-catenin responsiveness to pT81 comparable to that seen with the classic TCF-4 consensus sequence. Mutation of this TCF- 4 site on the gastrin promoter abrogates $\beta$-catenin responsiveness (Figure 1e). Taken together, these results indicate that gastrin expression is upregulated by the $\beta$-catenin/TCF- 4 signaling pathway, and the area responsible for this activity lies in the region -103 CCCATTCCT -93 on the gastrin promoter.

Overexpression of gastrin results in increased growth of polyps in $A P C^{\text {min-/+ }} \beta$-catenin-dependent polyposis. To assess the biological significance of gastrin upregulation by $\beta$ catenin, transgenic mice (MTI/G-Gly) overexpressing glycine-extended gastrin (G-Gly) (16) in the colon were a

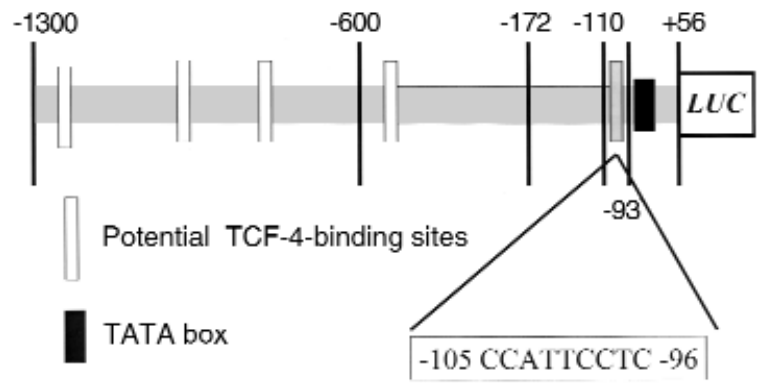

c

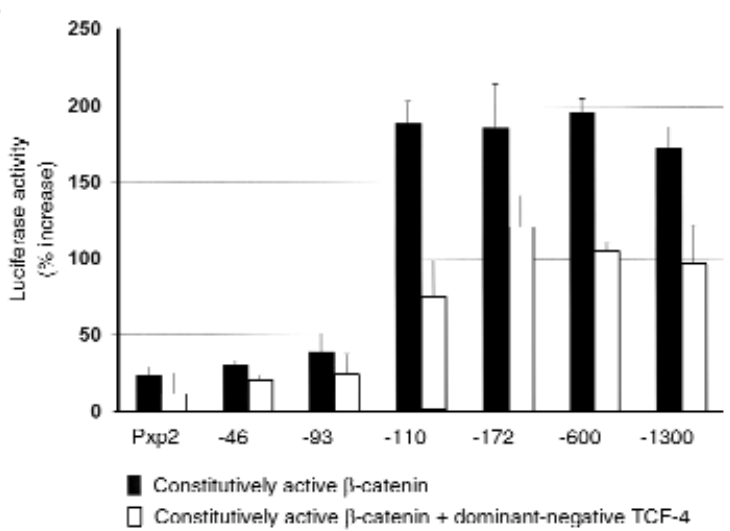

b

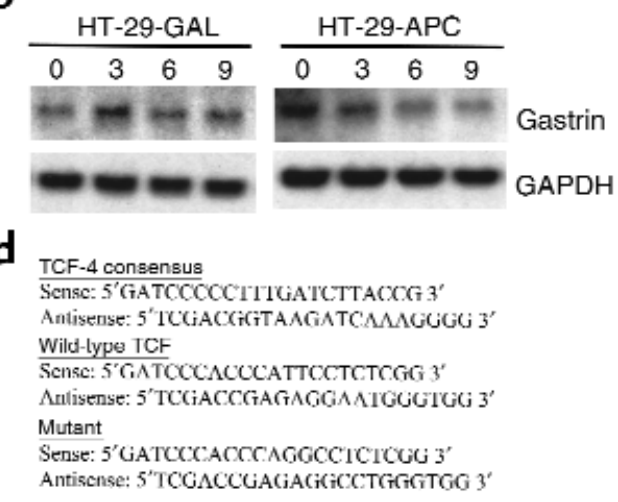

e

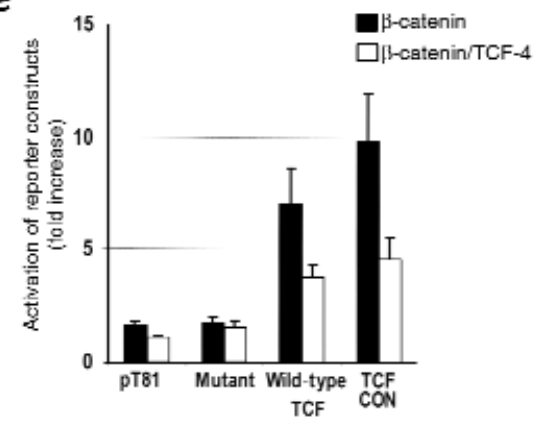

Figure 1

Gastrin is a downstream target of the APC/ $\beta$-catenin pathway. (a) Schematic representation of a 1,300-bp human gastrin promoter construct (19) containing several potential TCF-4-binding sites. TCF-4-binding sites with high homology to the known TCF/Lef-HMG box transcription factor consensus motifs $[C C(A / T) T T G(A / T)(A / T)(T / C)$; ref. 25, 27] were identified in the gastrin promoter using Lasergene99 DNA-analysis software. Homologous bases are printed as capital letters: -1166 tCTTGgca-1156, -1000 GATGAAACC-990, -822 aCTITGTcT-812, -516 CCATTGcTC -506, -103 CCATTccTC-93. (b) Northern blot analysis of RNA taken from HT-29-APC and HT-29-GAL cells that were induced with zinc to express either wild-type APC or $\beta$-galactosidase. The blot was probed with either a riboprobe to human gastrin exon 2 or GAPDH. (c) HeLa cells were transfected with a series of gastrin promoter-luciferase reporter deletion constructs (number reflects length of promoter from the transcriptional start site) and then cotransfected with a constitutively active $\beta$-catenin expression construct alone (filled bars) or with both the constitutively active $\beta$-catenin expression construct with a dominant-negative TCF- 4 construct (open bars). The basal promoter construct Pxp2 was used as a control. The results are taken from three independent experiments. (d) Sequences containing either the wild-type TCF-4-binding site from -103 to -90 on the gastrin promoter, a mutated TCF-4-binding site, or a corresponding perfect TCF-4 consensus sequence (Con) are shown. These sequences were used to generate heterologous promoter constructs by cloning them upstream of the thymidine kinase promoter in the luciferase reporter construct pT81. (e) HeLa cells were then transfected with the wild-type TCF-4-pT81 construct, the mutant TCF-4-pT81 construct, the consensus TCF-4-pT81 construct, or an empty pT81 construct and a constitutively active $\beta$-catenin expression construct (filled bars) or both the constitutively active $\beta$-catenin expression construct and a dominant-negative TCF-4 construct (open bars). 


\section{Figure 2}

Effect of overexpression of glycine-extended gastrin on APC min-/ mice. Total polyp number and the number of large polyps (>3 $\mathrm{mm}$ ) in the small intestine from twenty 6 -month-old APCmin-/+ mice that overexpress glycine-extended gastrin (MTI/G-Gly) (shaded bars) compared with twenty 6 -month-old control APC $\mathrm{Cin}^{-/+}$mice (filled bars) in the same genetic background ( $\left.{ }^{A} P<0.05\right)$.

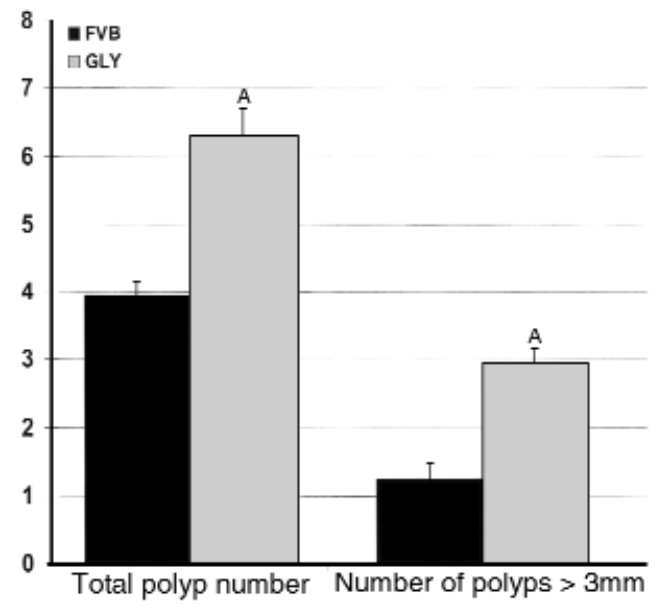

mated into the $\mathrm{APC}^{\mathrm{min}-/+}$ background. Glycine-extended gastrin is an incompletely processed form of gastrin strongly implicated in colonic proliferation (24), and the MTI/G-Gly mice show an increase in colonic proliferation, mucosal thickness, and goblet-cell hyperplasia

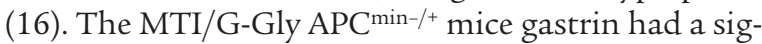
nificant increase in the total number of polyps in the small intestine $(6.30 \pm 0.39$ vs. $3.95 \pm 0.19, P<0.01)$ as well as a significant increase in the number of small intestinal polyps greater than $3 \mathrm{~mm}$ when compared with wild-type APC ${ }^{\mathrm{min}-/+}$ mice $(2.95 \pm 0.21$ vs. $1.25 \pm 0.21$, $P<0.01$ ) (Figure 2). This suggests that the incompletely processed forms of gastrin are important mediators of polyp growth and may also affect initiation of polyp formation in cells that are heterozygous for APC. There was no significant difference seen in the histology of polyps from MTI/G-Gly APC ${ }^{\mathrm{min}-/+}$ mice compared with those from control $\mathrm{APC}^{\mathrm{min}-/+}$ mice (data not shown). The overall number of polyps in both groups of mice was low, reflective of the poor penetrance of the $\mathrm{APC}^{\text {min-/+ }}$ mutation in the FVB background. In addition, there were virtually no colonic polyps seen in either the MTI/G-Gly or the wild-type $\mathrm{APC}^{\mathrm{min}-/+}$ mice, reflecting the previously reported poor penetrance of the $\mathrm{APC}^{\mathrm{min}-{ }^{++}}$mutation in the colon, preventing any meaningful statistical analysis of colonic polyposis.

Gastrin deficiency results in decreased growth and number of polyps in APC ${ }^{\text {min-/+ }}$ mice. To further define the role of gastrin in $\beta$-catenin-dependent polyposis, we examined the effect of gastrin deficiency on APC ${ }^{\text {min-/+ }}$ mice. C57BL/6× SV129 mice made gastrin deficient by targeted gene disruption (17) were mated into the $\mathrm{APC}^{\mathrm{min}-/^{+}}$background. Fifteen gastrin-deficient and 15 control $\mathrm{APC}^{\text {min-/+ }}$ mice

\section{Figure 3}

Effect of gastrin deficiency on APC ${ }^{\text {min-/+ }}$ mice. (a) Total polyp number in the small intestine and hematocrit from fifteen 6-month-old gastrindeficient APC min-/+ mice compared (shaded bars) with fifteen 6-monthold control APC ${ }^{\mathrm{min}-/+}$ mice (wild-type for the gastrin allele in the same genetic background; filled bars) ( $\left.{ }^{A} P<0.05\right)$. (b) The number of small intestinal polyps from the gastrin-deficient (shaded bars) and control APC ${ }^{\text {min-/+ }}$ mice (filled bars) as stratified by size $\left({ }^{A} P<0.05\right)$. were examined. The gastrin-deficient $\mathrm{APC}^{\mathrm{min}-/+}$ mice had $50 \%$ fewer polyps in the small intestine than control $\mathrm{APC}^{\mathrm{min}-{ }^{+}+}$mice $(8.53 \pm 0.97$ vs. $18.2 \pm 2.26, P<0.01)$. The gastrin-deficient $\mathrm{APC}^{\mathrm{min}-/+}$ mice had a higher hematocrit than control APC ${ }^{\mathrm{min}-/+}$ mice $(40.7 \pm 1.26 \%$ vs. $30.8 \pm 1.98 \%$, $P<0.05)$ (Figure 3a), likely related to decreased polyp numbers, resulting in decreased gastrointestinal blood loss. The difference in polyp number was more marked with increasing polyp size, with a threefold decrease seen

a

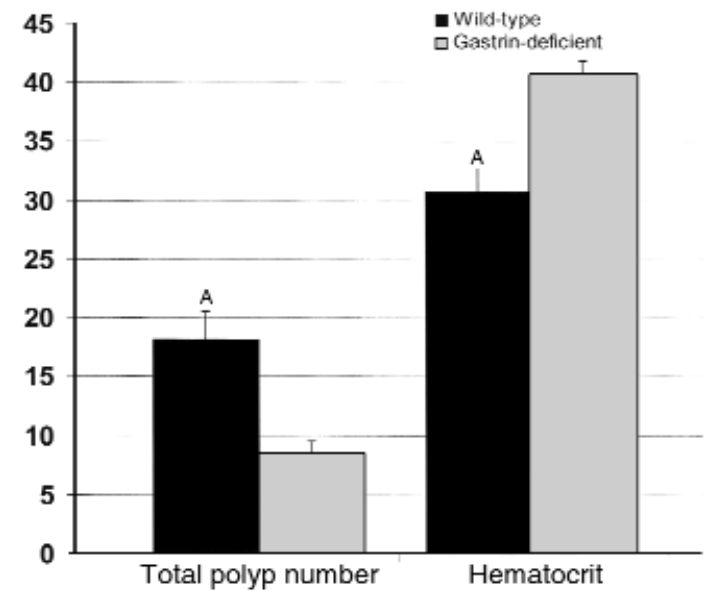

b

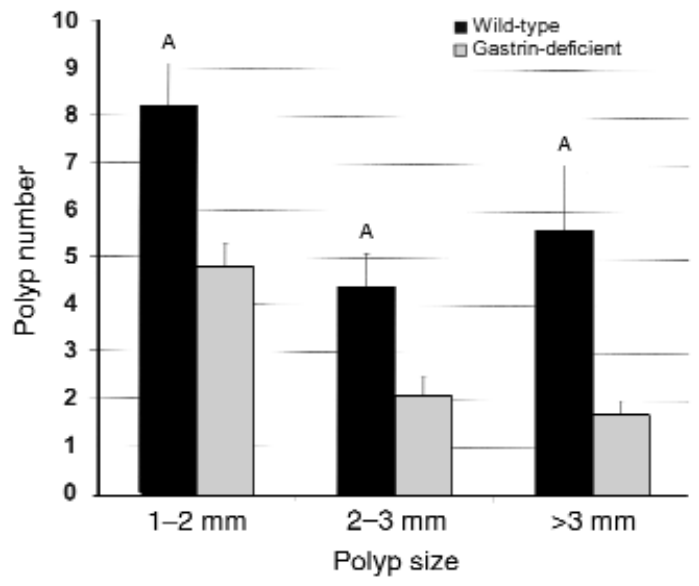


in the number of polyps larger than $3 \mathrm{~mm}(1.67 \pm 0.34 \mathrm{vs}$. $5.60 \pm 1.41, P<0.01$ ) found in gastrin-deficient $\mathrm{APC}^{\mathrm{min}-/+}$ mice compared with control mice (Figure $3 \mathrm{~b}$ ). As was the case for the MTI/G-Gly APC ${ }^{\mathrm{min}-{ }^{++}}$mice, there were virtually no polyps seen in the colon of either the gastrin-deficient or control APC ${ }^{\mathrm{min}-/+}$ mice.

Gastrin deficiency resulted in decreased proliferation in the polyps of APC ${ }^{\text {min-/+ }}$ mice. To determine if the difference in polyp size was due to differences in proliferation, proliferation rates were assessed by assaying incorporation of BrdU using immunohistochemical methods. The polyps of gastrin-deficient mice had a significant decrease in proliferation compared with polyps from wild-type mice (Figure 4, a-c). Interestingly, the difference in proliferation is more marked with advanced polyp size, supporting the notion that during polyp development, gastrin is upregulated by $\beta$-catenin to mediate growth.

Gastrin deficiency did not affect ras-induced polyp growth. It has been reported recently that gastrin gene expression is also upregulated by activated $\operatorname{ras}(24)$. Activated ras mutations generally occur downstream of APC mutations and are found in $50 \%$ of advanced intestinal polyps. If gastrin is an important mediator of ras-induced polyp growth, then it might be expected that whereas ras mutations may develop at an equal rate in gastrin-deficient and control $\mathrm{APC}^{\mathrm{min}-/_{+}}$mice, the activated ras mutations would not result in polyp growth in gastrin-deficient mice. In this scenario, large polyps that develop in gastrin-deficient $\mathrm{APC}^{\mathrm{min}-/+}$ mice would be largely ras-independent, and as a result there would be a decreased frequency of ras mutations in the large polyps of gastrin-deficient mice when compared with control mice. However, we found no significant difference in the frequency of ras mutations in codon 12 , the predominant mutation found in mice (22), seen in the large polyps of the gastrin-deficient $\mathrm{APC}^{\mathrm{min}-/+}$ mice compared with wild-type $\mathrm{APC}^{\mathrm{min}-{ }^{+}+}$mice $(76.7 \%$ vs. $73.3 \%)$. These results support the notion that gastrin is not a necessary mediator of ras-induced polyp growth.

Gastrin deficiency led to an increase in life expectancy in $A P C^{\text {min-/+ }}$ mice. The effect of gastrin deficiency on $\beta$ catenin/TCF-4-dependent polyp growth led to significant differences in life expectancy. Gastrin-deficient $\mathrm{APC}^{\mathrm{min}-/+}$ mice and corresponding wild-type $\mathrm{APC}^{\mathrm{min}-/^{+}}$ mice were followed until death and survival curves were calculated. The gastrin-deficient $\mathrm{APC}^{\mathrm{min}-/+}$ mice had a significantly increased survival when compared with wild-type mice $(216.7 \pm 6.06$ vs. $195.9 \pm 4.67$ days, $P<0.05)$ (Figure 5).

\section{Discussion}

In summary, we have shown that gastrin expression is upregulated directly through the $\beta$-catenin/TCF-4 signaling pathway, which accounts for earlier observations that gastrin, like $c-m y c$ and cyclin D1, is upregulated during colon cancer progression (11). We have narrowed the $\beta$-catenin/TCF-4 response element to an area between -110 and -93 of the human gastrin promoter. Using Lasergene99 DNA-analysis software (DNASTAR, Madison, Wisconsin, USA) an element -103 CCATTc-
cTC-93 within this region was found that has $80 \%$ homology to known Tcf/Lef-HMG box transcriptionfactor consensus motifs [CC(A/T)TTG(A/T)(A/T)(T/C)] $(25-27)$. This element was able to confer $\beta$-catenin responsiveness when placed upstream of the thymidine kinase promoter, and mutation of this site abolishes $\beta$ catenin responsiveness. This is comparable to similar elements found on the $c-m y c$, cyclin D1, and PPAR $\delta$ that mediate $\beta$-catenin responsiveness and explains the finding reported previously that gastrin is upregulated in $\mathrm{APC}^{\mathrm{min}-{ }^{++}}$derived polyps (11).

Whereas it is likely that previously identified targets of $\beta$-catenin (c-myc, cyclin D1, and PPAR $\delta$ ) are important in the development of intestinal polyps, the precise functional roles for these other targets have not been defined through genetic approaches in vivo. In this study we have found that over-expression of glycineextended gastrin in $\mathrm{APC}^{\mathrm{min}-/+}$ mice results in increased number and size of polyps and that gastrin deficiency in the $\mathrm{APC}^{\mathrm{min}-/+}$ mouse model leads to decreased polyp number and size, decreased proliferation rates within the polyps, and increased survival. These findings are similar to the effect of COX-2 deficiency on polyposis (28); the precise relationship of gastrin expression to
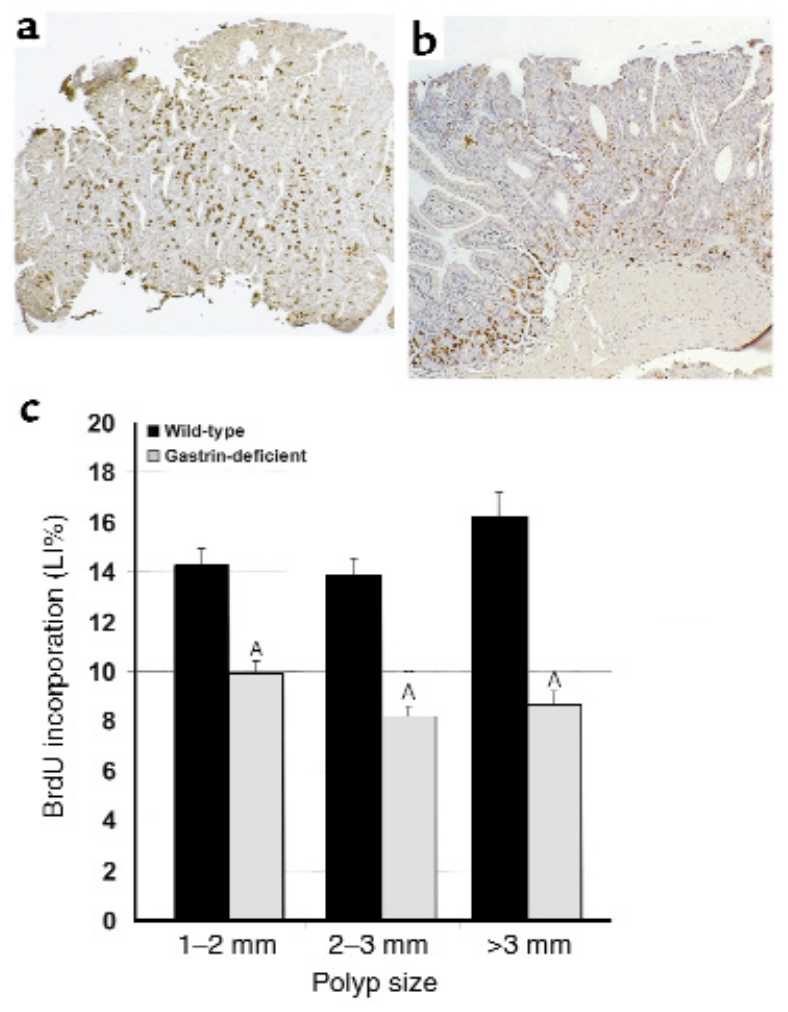

Figure 4

Effect of gastrin deficiency on polyp proliferation rates. (a) BrdU staining in 6-month old gastrin-deficient APC min-/+ mice and (b) control APC $\mathrm{min}-/+^{+}$mice. (c) Labeling indices were calculated by counting the number of immunopositive-staining cells as a percentage of the total number of cells in each polyp $\left({ }^{A} P<0.05\right)$ from both wild-type (filled bars) and gastrin-deficient mice (shaded bars). 


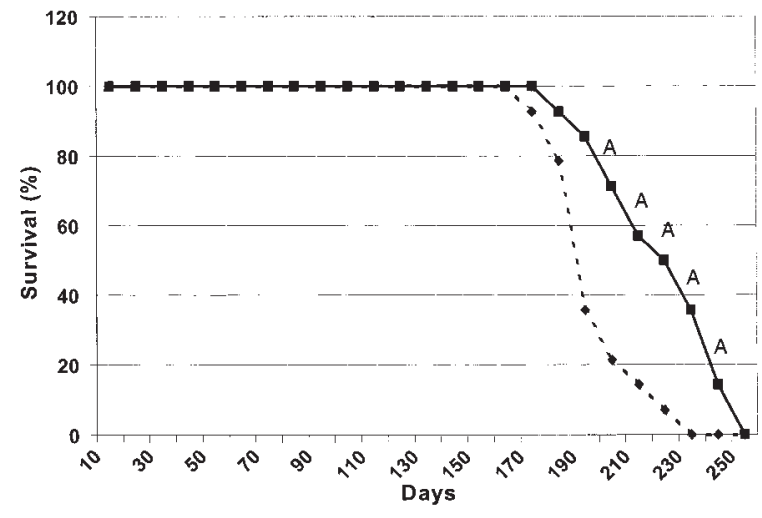

Figure 5

Effect of gastrin deficiency on life expectancy. Survival curves from $15 \mathrm{APC}^{\mathrm{min}-/^{+}}$gastrin-deficient mice and 15 control $\mathrm{APC}$ min-/+ mice $\left({ }^{A} P<0.05\right)$.

COX-2 activity remains undefined. Taken together, these findings suggest that gastrin is an important mediator of $\beta$-catenin-dependent polyp growth.

The increase in polyp growth is likely mediated by the less-processed forms of gastrin. This is supported by our observation that mice overexpressing glycineextended gastrin (MTI/G-Gly) exhibit significant increases in the number and size of polyps. G-Gly and progastrin are the predominant form of gastrin found in colorectal cancers $(12,13)$ and the normal colon $(14)$. Studies in cell lines (22), as well as in transgenic mice $(15,16)$, have shown that these incompletely processed forms of gastrin can act as trophic factors for colon cancers as well as the normal colon. G-Gly likely exerts this effect independent of the classical CCK-B/gastrin receptor, possibly through pathways involving c-jun (29), PI-3-kinase (30), and/or p70S6K (30). However, the precise identity of the receptor for the less processed forms of gastrin remains unclear, although three candidate receptors for the less processed form of gastrin have been identified (31-33). Whereas a role for amidated gastrin (G-17) cannot be completely excluded, the normal colon does not appear to express the classic CCK-B/gastrin receptor (34), and expression of this receptor has been found in only a minority of colon cancers as measured by RT-PCR, although wide variability has been reported (17-57\%) reflecting the difficulties inherent in RT-PCR analysis. (33, 35-39).

The trophic role of the lessprocessed forms of gastrin in intestinal polyps is further supported by proliferation studies performed on the polyps of the gastrin-deficient and wild-type $\mathrm{APC}^{\mathrm{min}-/+}$ mice. The gastrin-deficient mice had a significant decrease in polyp proliferation rates when compared with control mice when controlled for polyp size, with more marked decreases seen with increasing polyp size. The trophic effect of the lessprocessed forms of gastrin on intestinal polyps, as evidenced by the proliferation studies and the differences seen in the average size of polyps, suggest that they are important in colon cancer promotion. The decrease in the total number of intestinal polyps in the gastrin-deficient $\mathrm{APC}^{\mathrm{min}-/^{+}}$mice and the increase in the number of polyps in the MTI/G-Gly mice also raise the possibility that gastrin may also be important in the early stages of polyp development.

Activated ras mutations have been detected in up to $50 \%$ of advanced intestinal polyps and is thought to be important in colon cancer promotion in this subset of polyps (40). It has been reported that ras can upregulate gastrin expression (23), although the importance of gastrin in ras-mediated polyp growth has not been demonstrated clearly. We find that gastrin deficiency did not select for the subset of large polyps with wild-type ras (rates of ras mutations in large polyps were equal in the gastrin-deficient and control mice), suggesting that whereas ras can upregulate gastrin expression, it is not essential for ras-mediated growth. Thus, whereas gastrin is clearly a downstream target of APC $/ \beta$-catenin, further studies will be required to determine whether gastrin is upstream or downstream of ras in the multi-hit hypothesis of colon cancer progression $(41,42)$ (Figure 6).

Our results would suggest that progastrin-derived peptides might serve as useful therapeutic targets in the treatment of colon cancer. Potential therapies that have been shown to inhibit growth of colon cancer cell lines include possible G-Gly receptor antagonists (43), antisense gastrin cDNA constructs (44), and immunoneutralizing antibodies to gastrin (45). Since progastrin also exhibits colonic trophic activity (15), the ideal therapeutic agent should be able to neutralize both progastrin and glycine-extended gastrin.

Taken together, we propose that gastrin is an important downstream target of $\beta$-catenin/TCF- 4 and that the less-processed forms of gastrin function as important mediators of intestinal polyp growth and colorectal cancer promotion. The identification of gastrin as a functionally relevant downstream target of the $\beta$ -

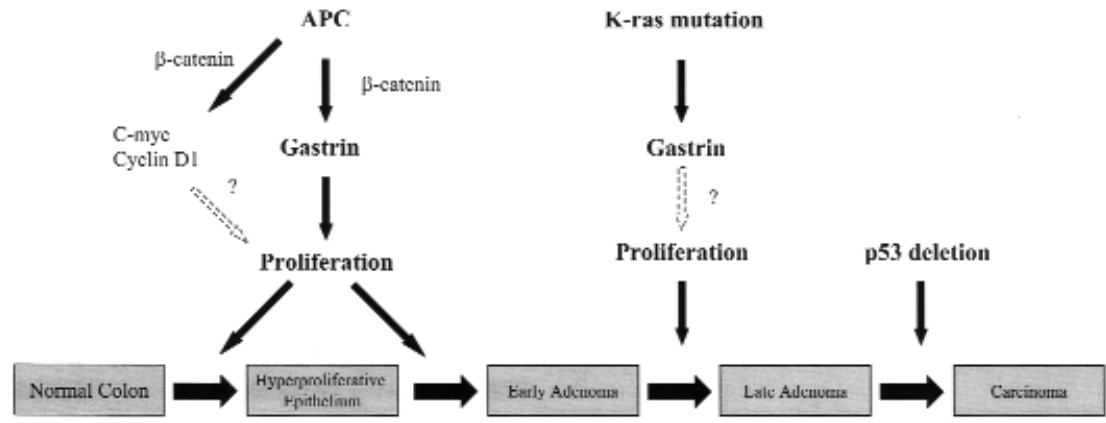

Figure 6

A role for gastrin in the molecular pathogenesis of colorectal cancer. 
catenin/TCF-4 pathway strengthens the importance of gastrin as a potential target for novel therapeutic modalities in the treatment of colorectal cancer.

\section{Acknowledgments}

This study was supported by grants from the NIH to T.J. Koh (K08 DK-02545-01) and T.C. Wang (R01 DK52778). A. Varro and G.J. Dockray were supported by grants from the Medical Research Council and Wellcome Trust. C.J. Bulitta is supported by a scholarship of the Deutsche Forschungsgemeinschaft (Bu 1181/1-1).

1. Smith, K.J., et al. 1993. The APC gene product in normal and tumor cells. Proc. Natl. Acad. Sci. USA. 90:2846-2850.

2. Kinzler, K.W., and Vogelstein, B. 1996. Lessons from hereditary colorectal cancer. Cell. 87:159-170.

3. Morin, P.J., et al. 1997. Activation of $\beta$-catenin-Tcf signaling in colon cancers by mutations in $\beta$-catenin or APC. Science. 275:1787-1790.

4. Korinek, V., et al. 1997. Constitutive transcriptional activation by a $\beta$ catenin-Tcf complex in APC-/- colon carcinoma. Science. 275:1784-1787

5. Molenaar, M., et al. 1996. XTcf-3 transcription factor mediates $\beta$ catenin-induced axis formation in Xenopus embryos. Cell. 86:391-399.

6. Behrens, J., et al. 1996. Functional interaction of $\beta$-catenin with the transcription factor LEF-1. Nature. 382:638-642.

7. Korinek, V., et al. 1999. Depletion of epithelial stem-cell compartments in the small intestine of mice lacking Tcf-4. Nat. Genet. 19:379-383.

8. He, T.C., et al. 1998. Identification of c-myc as a target of the APC pathway. Science. 281:1509-1512

9. Tetsu, O., and McCormick, F. 1999. $\beta$-catenin regulates expression of cyclin D1 in colon carcinoma cells. Nature. 398:422-426.

10. He, T.C., Chan, T.A., Vogelstein, B., and Kinzler, K.W. 1999. PPAR $\delta$ is an APC regulated target of nonsteroidal anti-inflammatory drugs. Cell. 99:335-345.

11. Watson, S.A., Michaeli, D., Morris, R.M., McWilliams, D., and Smith, A.M. 1999. The role of gastrin in the adenoma: carcinoma sequence in the colon. Digestion. 60:600. (Abstr.)

12.Nemeth, J., Taylor, B., Pauwels, S., Varro, A., and Dockray, G.J. 1993. Iden tification of progastrin derived peptides in colorectal carcinoma extracts. Gut. 34:90-95.

13. Van Solinge, W.W., Nielsen, F.C., Friis-Hansen, L., Falkmer, U.G., and Rehfeld, J.F. 1993. Expression but incomplete maturation of progastrin in colorectal carcinoma. Gastroenterology. 104:1099-1107.

14. Luttichau, H.R., van Solinge, W.W., Nielsen, F.C., and Rehfeld, J.F. 1993. Developmental expression of the gastrin and cholecystokinin genes in rat colon. Gastroenterology. 104:1092-1098.

15. Wang, T.C., et al. 1996. Processing and proliferative effects of human progastrin in transgenic mice. J. Clin. Invest. 98:1918-1929.

16. Koh, T.J., et al. 1999. Overexpression of glycine-extended gastrin in transgenic mice results in increased colonic proliferation. J. Clin. Invest. 103:1119-1126

17. Koh, T.J., et al. 1997. Gastrin deficiency results in altered gastric differentiation and decreased colonic proliferation in mice. Gastroenterology. 113:1015-1025.

18. Morin, P.J., Vogelstein, B., and Kinzler, K.W. 1996. Apoptosis and APC in colorectal tumorigenesis. Proc. Natl. Acad. Sci. USA. 93:7950-7954.

19. Tillotson, L.G., Wang, T.C., and Brand, S.J. 1994. Activation of gastrin transcription in pancreatic insulinoma cells by a CACC promoter element and a 70-kDa sequence-specific DNA-binding protein. J. Biol. Chem. 269:2234-2240.

20. Kolligs, F.T., Hu, G., Dang, C.V., and Fearon, E.R. 1999. Neoplastic transformation of RK3E by mutant $\beta$-catenin requires deregulation of Tcf/Lef transcription but not activation of c-myc expression. Mol. Cell. Biol. 19:5696-5706.

21. Luongo, C., Moser, A.R., Gledhill, S., and Dove, W.F. 1994. Loss of APC in intestinal adenomas from Min mice. Cancer Res. 54:5947-5952.

22. Zaidi, N.H., et al. 1995. Transgenic expression of human MGMT protects against azoxymethane-induced aberrant crypt foci and $\mathrm{G}$ to $\mathrm{A}$ mutations in the K-ras oncogene of mouse colon. Carcinogenesis. 16:451-456.

23. Nakata, H., Wang, S.L., Chung, D.C., Westwick, J.K., and Tillotson, L.G. 1998. Oncogenic ras induces gastrin gene expression in colon cancer. Gastroenterology. 115:1144-1153.

24. Hollande, F., et al. 1997. Glycine-extended gastrin acts as an autocrine growth factor in a nontransformed colon cell line. Gastroenterology. 113:1576-1588.

25. Giese, K., Cox, J., and Grosschedl, R. 1992. The HMG domain of lymphoid enhancer factor 1 bends DNA and facilitates assembly of functional nucleoprotein structures. Cell. 69:185-195.

26. Roose, J., and Clevers, H. 1999. TCF transcription factors: molecular switches in carcinogeneis. Biochim. Biophys. Acta. 1424:M23-M37.

27. van de Wetering, M., Oosterwegael, M., Dooijies, D., and Clevers, H. 1991. Identification and cloning of TCF-1, a T lymphocyte specific transcription factor containing a sequence-specific HMG box. EMBO J. 10:123-132.

28. Oshima, M., et al. 1996. Suppression of intestinal polyposis in APC $\Delta 716$ knockout mice by inhibition of cyclooxygenase 2. Cell. 87:803-809.

29. Todisco, A., Takeuchi, Y., Seva, C., Dickinson, C.J., and Yamda, T. 1995. Gastrin and glycine-extended progastrin processing intermediates induce different programs of early gene activation. J. Biol. Chem. 270:28337-28341

30. Kowalski-Chauvel, A., Pradayrol, L., Vaysse, N., and Seva, C. 1997. Tyrosine phosphorylation of insulin receptor substrate- 1 and activation of the PI-3-kinase pathway by glycine-extended gastrin precursors. Biochem. Biophys. Res. Commun. 236:687-692.

31. Seva, C., Dickinson, C.J., and Yamada, T. 1995. Growth promoting effects of glycine-extended progastrin. Science. 265:410-412.

32. Singh, P., Owlia, A., Espejo, R., and Dai, B. 1995. Novel gastrin receptor mediates mitogenic effects of gastrin and processing intermediates of gastrin in Swiss 3 T3 fibroblasts. J. Biol. Chem. 270:28337-28341.

33. Baldwin, G.S. 1995. Binding of progastrin fragments to the $78-\mathrm{kDa}$ binding protein. FEBS Lett. 359:97-100.

34. Biagini, P., et al. 1997. The human gastrin/cholecystokinin receptors: type B and type C expression in colonic tumors and cell lines. Life Sci. 61:1009-1018.

35. Monstein, H.J., et al. 1996. Cholecystokinin-A and cholecystokinin$\mathrm{B} /$ gastrin receptor mRNA expression in the gastrointestinal tract and pancreas of the rat and man. Scand. J. Gastroenterol. 31:383-390.

36. Frucht, H., Gazdar, F., Park, J.A., Oie, H., and Jensen, R.T. 1992. Characterization of functional receptors for gastrointestinal hormones on human colon cancer cells. Cancer Res. 52:1114-1122.

37. Clerc, P., et al. 1997. Differential expression of the CCK-A and CCK$\mathrm{B} /$ gastrin receptor genes in human cancers of the esophagus, stomach, and colon. Int. J. Cancer. 72:931-936.

38. Watson, S.A., et al. 1998. Expression of CCKB/gastrin receptor isoforms in gastro-intestinal tumour cells. Int. J. Cancer. 77:572-577.

39. Upp, J.R., Singh, P., Townsend, C.M., and Thompson, J.C. 1989. Clinical significance of gastrin receptors in human colon cancers. Cancer Res. 49:488-492.

40. Guan, R.J., Fu, Y., Holt, P.R., and Pardee, A.B. 1999. Association of k-ras mutations with p16 methylation in human colon cancer. Gastroenterology. 116:1063-1071

41. Vogelstein, B., et al. 1988. Genetic alterations during colorectal-tumor development. N. Engl. J. Med. 319:525-532.

42. Fearon, E.R. 1995. Molecular genetics of colorectal cancer. Ann. NY Acad. Sci. 768:101-109.

43. Lityak, J.A., et al. 1999. JMV1155: a novel inhibitor of glycine-extended progastrin-mediated growth of a human colon cancer in vivo. Anticancer Res. 19:45-49.

44. Singh, P., et al. 1996. Gastrin gene expression is required for the proliferation and tumorigenicity of human colon cancer cells. Cancer Res. 56:4111-4115.

45. Watson, S.A., et al. 1996. Gastrimmune raises antibodies that neutralize amidated and glycine-extended gastrin-17 and inhibit the growth of colon cancer. Cancer Res. 56:880-885. 